\title{
Express analysis of endohedral fullerenes amount contained at fullerene mixture
}

\author{
G. N. Churilov ${ }^{1,3}$, A. A. Popov ${ }^{2}$, U.E. Guliaeva ${ }^{1,3}$, N. A. Samoylova ${ }^{2}$, N. G. Vnukova ${ }^{1,3}$, \\ A. L. Kolonenko ${ }^{1}$, V. G. Isakova ${ }^{1}$, A. I. Dudnik ${ }^{1,3}$, V. S. Koravanets ${ }^{3}$ \\ ${ }^{1}$ Kirensky Institute of Physic SB RAS, Krasnoyarsk, Russia \\ ${ }^{2}$ Leibniz Institute for Solid State and Materials Research, Dresden, Germany \\ ${ }^{3}$ Siberian Federal University, Krasnoyarsk, Russia \\ churilov@iph.krasn.ru
}

PACS 32.30; 52.50

DOI 10.17586/2220-8054-2016-7-1-140-145

This paper describes the technique for rapid determination of endohedral metallofullerene (EMF) content in a fullerene mixture (FM). The methods of mass spectroscopy and atom emission element analysis underlay at the technique. By the method of mass spectroscopy, the type of EMF with atom-guest is registered and by the method of emission spectroscopy, the quantity of that element which is contained in the FM is determined. The technique may be used for rapid determination of EMF weight percents in the FM in the specific case if only one type of EMF is present, and of EMF average content if there are different types of EMF are present. The technique is demonstrated through the example of analysis of FM with $\mathrm{Y}$, which was extracted from the carbon condensate (CC) by different solvents $\left(\mathrm{C}_{5} \mathrm{H}_{5} \mathrm{~N}\right.$ and $\left.\mathrm{CS}_{2}\right)$.

Keywords: endohedral fullerene, atom emission spectroscopy, quantitative assessment.

Received: 20 November 2015

\section{Introduction}

If common fullerenes, such as $\mathrm{C}_{60}, \mathrm{C}_{70}$, and type $\mathrm{C}_{2 n}$ in general are widely studied and have already been frequently used, then we cannot say the same about EMF. Although it is theoretically predicted that they have unique features, able to resolve a number of problems with electronics, computing technologies, medicine, mechanical engineering etc [1]. Of particular significance is the future implementation of EMF with enclosed magnetic and radioactive atoms which may have utility in medicine for diagnostic and therapeutic purposes [2].

Insufficient knowledge of these substances' features is a result of their lack of production in quantities sufficient for full-scale research. In the literature, there are results given for obtaining a carbon condensate (CC) containing EMF, and methods for their isolation [3]. Nevertheless, the search for synthesis and isolation methods is ongoing, as known methods of today are inadequate. The situation is exacerbated by the complexity and significant amount of time required for the analysis of EMF in the selective FM. This slows down the process of determining how synthetic parameters exert influence upon the content of the EMF formed under these parameters and the efficiency of the used fabrication method. The direct method involves chromatographic separation, analysis and determination of the weight fractions by percentage of EMF. There are works in which the extinction of solutions containing a certain type of EMF is determined [4]. However, this method also requires the use of a direct method as well as a chromatographic separation method. Determination of EMF content in the fullerene mixture by our method obviates the need for the time-consuming procedure of chromatographic fractionation with subsequent mass spectroscopic investigation and weighing. The developed 
method has been applied by us to study the contents of EMF with $\mathrm{Y}$ in fullerene mixture, synthesized at different helium pressures and separated by the solvents $\mathrm{C}_{5} \mathrm{HC}_{5} \mathrm{~N}$ and $\mathrm{CS}_{2}$.

\section{Experimental part}

CC was synthesized using a high frequency (HF) arc plasma for sputter graphitic electrodes (graphitic rods) [5,6]. Graphitic rods, with an axial hole in which $\mathrm{Y}_{2} \mathrm{O}_{3}$ was placed, were annealed at $1800^{\circ} \mathrm{C}$ for $20 \mathrm{~min}$. Current arc was $190 \mathrm{~A}$, frequency $-66 \mathrm{kHz}$, and chamber pressure was: $353,98,64.8$ or $32.4 \mathrm{kPa}$. CC with Y synthesized under different pressures were portioned into two parts. Extraction of one part was carried out with $\mathrm{C}_{5} \mathrm{H}_{5} \mathrm{~N}$ and the other with $\mathrm{CS}_{2}$. According to our technique, the FM, after careful filtering, was dried. With the help of emission spectroscopy, the metal content (the atoms of which were the atoms-guests in the EMF) was determined for the FM.

Atomic-emission analysis was performed on the setup, consisting of plasma atomizer HF discharge in a stream of argon with copper and graphite electrodes, the spectrograph PGS-2 and a computerized spectral registration. Samples were made and concentration-response curves were constructed for $\mathrm{Y}$ over a concentration range from $1 \cdot 10^{-5}$ to $1.0 \mathrm{~g} / \mathrm{l}$. Samples were made as follows: in graphite rods with a diameter of $6 \mathrm{~mm}$ were drilled apertures of $4 \mathrm{~mm}$ diameter and $5 \mathrm{~mm}$ of depth. Apertures with a solution containing a substance with a known concentration of $\mathrm{Y}$ were dried. Thus, prepared samples act as graphite electrodes. Based on the analysis of the emission spectrum at the Y $324.23 \mathrm{~nm}$ line, an analytical curve was constructed (Fig. 1). The analytic curve is relevant for all types of compositions because samples are completely atomized during analysis [7].

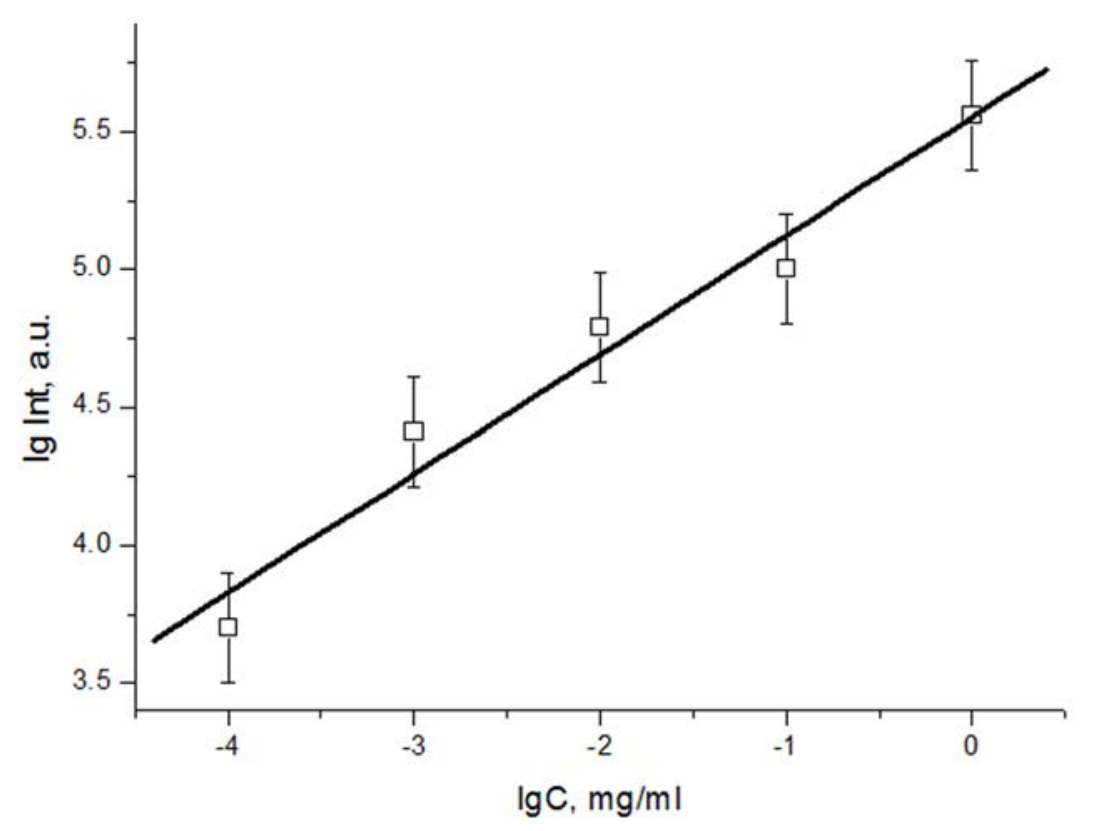

FIG. 1. Analytical curve for Y determination at the carbon

Fullerene extracts from the $\mathrm{CC}$ with a known concentration of $\mathrm{Y}$ were also applied in the apertures of the graphite rods, as was done in the preparation of samples, and they also acted as graphite electrodes. The content of yttrium in the sample was then determined by the intensity of the yttrium $324.23 \mathrm{~nm}$ line and the concentration curve was generated (Figs 3a, 4a). 
The mass spectra of FM samples (Bruker BIFLEXTM III Time-of-Flight mass spectrometer with laser desorption) shows the presence of pure fullerenes and fullerene with $\mathrm{Y}$. However, $\mathrm{Y}(88.9 \mathrm{~m} / \mathrm{z}), \mathrm{YC}_{2}(112.9 \mathrm{~m} / \mathrm{z}), \mathrm{Y}_{3} \mathrm{C}(278.7 \mathrm{~m} / \mathrm{z})$ and etc. were not registered (Fig. 2)

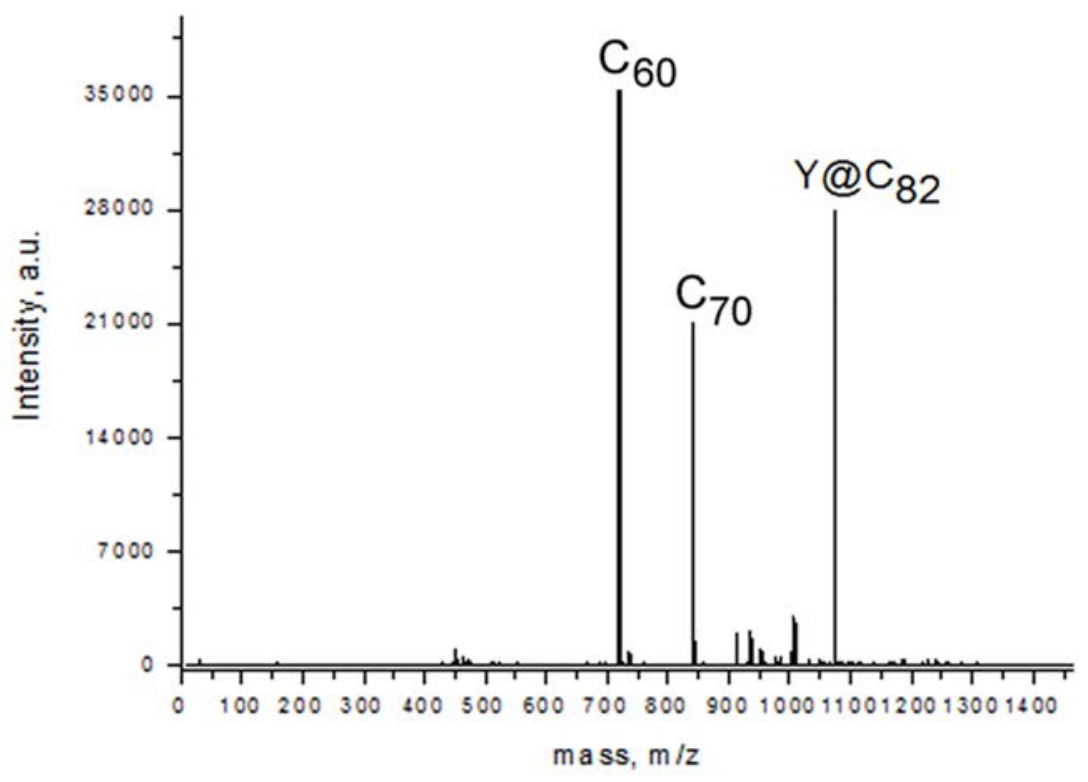

FIG. 2. Mass spectral (positive-ion) analysis of FM synthesized with $\mathrm{Y}_{2} \mathrm{O}_{3}$

Mass spectroscopic investigation provided information on the qualitative composition of the synthesized EMF (Figs. 3b, 4b). For pressure 353 and $98 \mathrm{kPa}$, it was discovered that the yttrium occurs in the obtained fullerene mixture only in the form $\mathrm{Y} @ \mathrm{C}_{82}$. Accordingly, the content of $\mathrm{Y} @ \mathrm{C}_{82}$ was easily calculated by the content of $\mathrm{Y}$.

This technique allows one to obtain a quantitative assessment, if electromagnetic filter with one metal atom molecule was formed. However, with metal addition, there are often several types of EMF that are formed simultaneously. Mass spectroscopic investigation shows that there are three types of EMF: Y@ $\mathrm{C}_{82}, \mathrm{Y}_{2} @ \mathrm{C}_{82}, \mathrm{Y}_{2} \mathrm{C}_{2} @ \mathrm{C}_{82}$ (Figs. 5a, 5b and 6a, 6b) in the $\mathrm{CC}$ synthesized under $64.8 \mathrm{kPa}$ pressure. In this instance, this technique may also be used, but for average assessment only. We have a qualitative assessment of EMF formation efficiency for those synthesis parameters, but have no information about the amounts of the specific types of EMF synthesized in the process.

Table 1 shows the results of $\mathrm{Y}$ and $\mathrm{Y} @ \mathrm{C}_{82}$ content in the fullerene mixtures extracted from $\mathrm{CC}$ synthesized at different pressures and extracted by different solvents $\left(\mathrm{C}_{5} \mathrm{H}_{5} \mathrm{~N}\right.$ or $\left.\mathrm{CS}_{2}\right)$.

Accordingly, the quantitative assessment of EMF may be carried out without fractionation using HPLC, with future determination of fraction characteristics and weighing.

There are the following possible scenarios: 1 - if mass spectral investigation showed that only one type of EMF was formed, then it is easy to calculate the quantitative assessment of EMF by determining the percent content of inputting element; 2 - if mass spectral investigation showed that there are several types of EMF, then to determine the percent content of inputting element, we have only the average assessment of EMF content. In subsequent work, we plan to remove that ambiguity by adding photoelectron spectroscopy to our technique for quantitative assessment of several types of EMF content that was contained in the analyzed FM. 

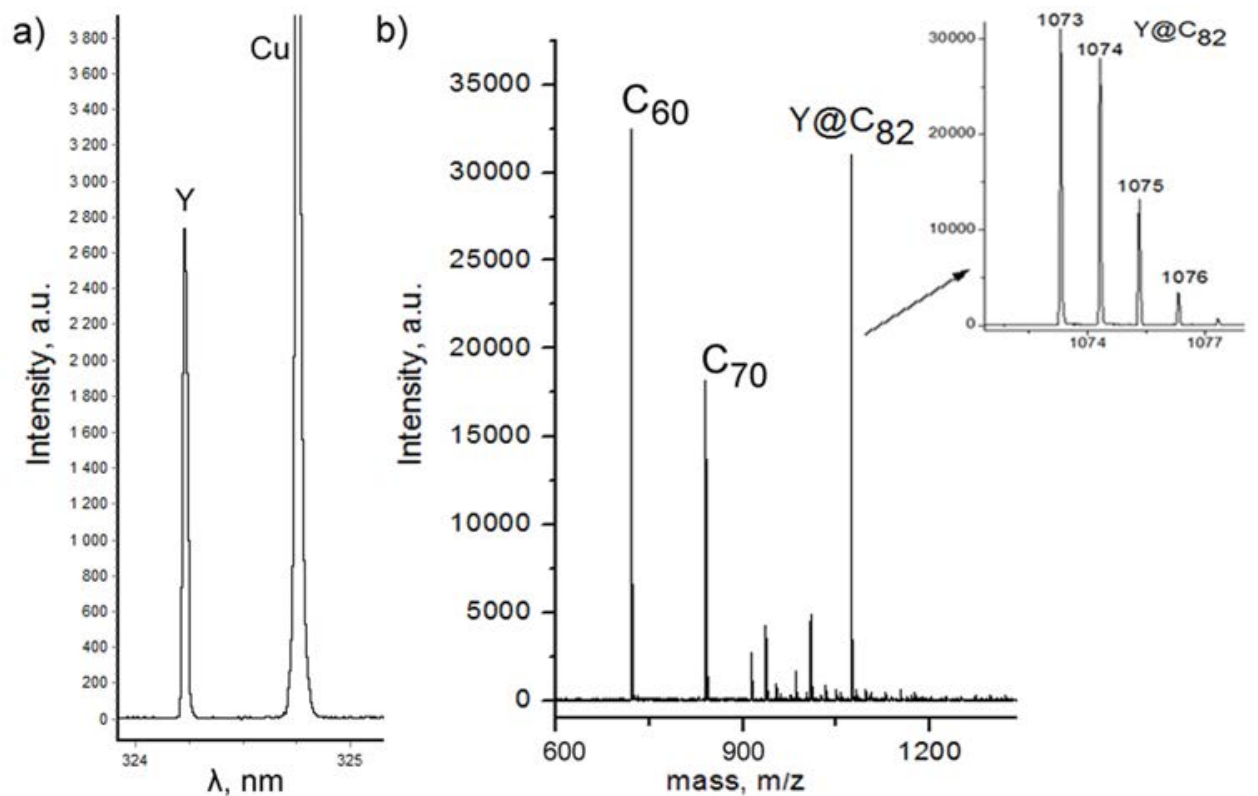

FIG. 3. Results of atom emission and positive-ion mass spectral analysis of FM synthesized with $\mathrm{Y}_{2} \mathrm{O}_{3}$ under $98 \mathrm{kPa}$ and extracted by $\mathrm{C}_{5} \mathrm{H}_{5} \mathrm{~N}$ : a) part of atom emission spectrum, b) part of mass spectrum (on insertion - $\mathrm{Y} @ \mathrm{C}_{82}$ )
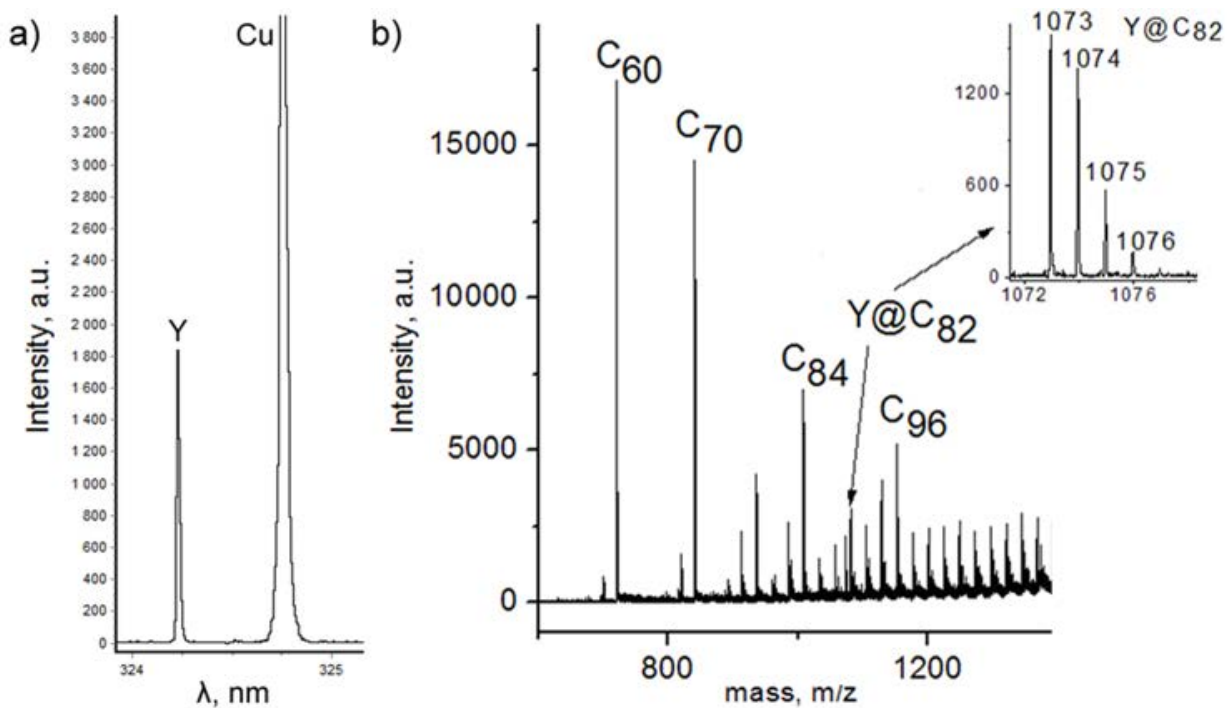

FIG. 4. Results of atom emission and positive-ion mass spectral analysis of FM synthesized with $\mathrm{Y}_{2} \mathrm{O}_{3}$ under $98 \mathrm{kPa}$ and extracted by $\mathrm{CS}_{2}$ a) part of atom emission spectrum, b) part of mass spectrum (on insertion- $\mathrm{Y} @ \mathrm{C}_{82}$ ) 

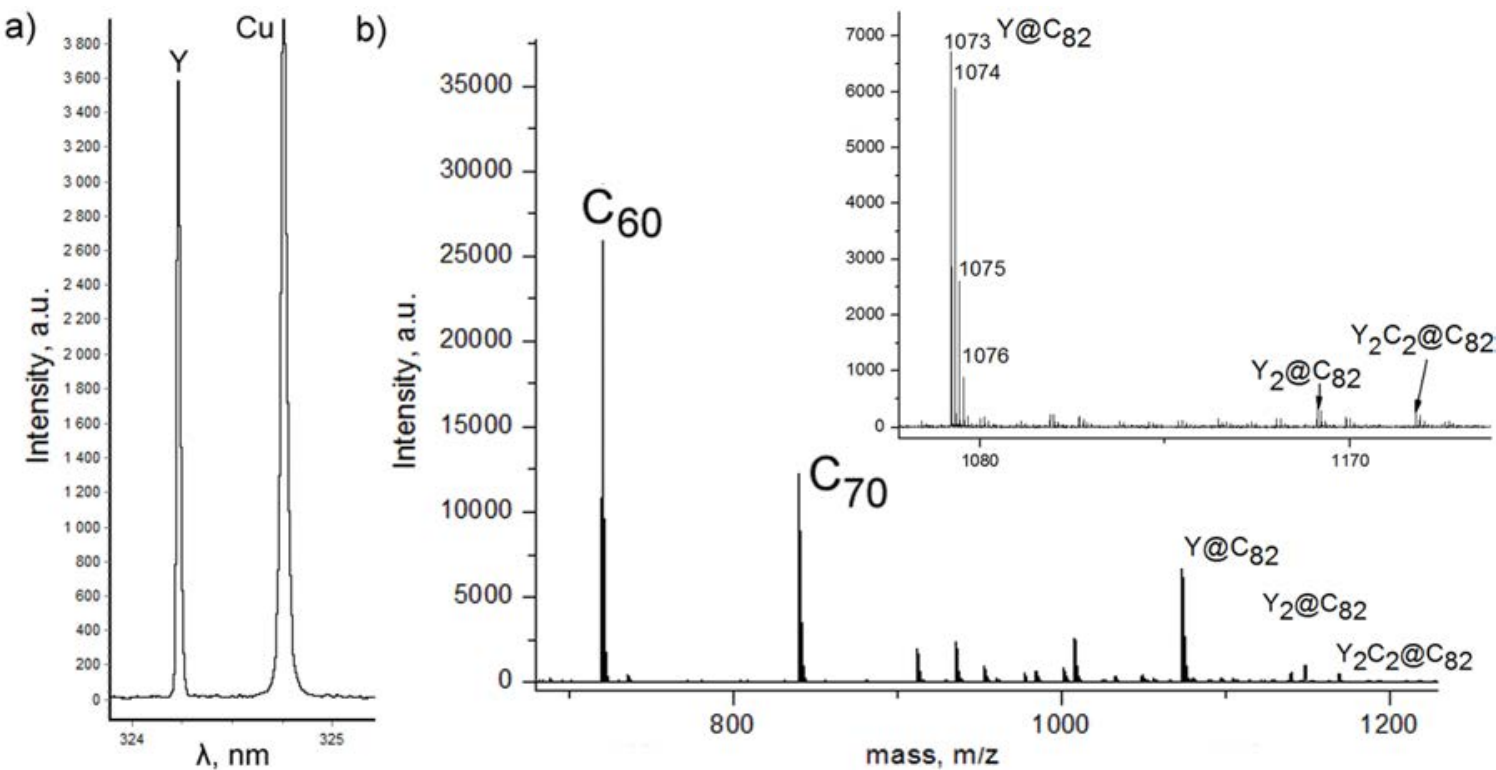

FIG. 5. Results of atom emission and positive-ion mass spectral analysis of FM synthesized with $\mathrm{Y}_{2} \mathrm{O}_{3}$ under $64.8 \mathrm{kPa}$ and extracted by $\mathrm{C}_{5} \mathrm{H}_{5} \mathrm{~N}$ a) part of atom emission spectrum, b) part of mass spectrum

a)

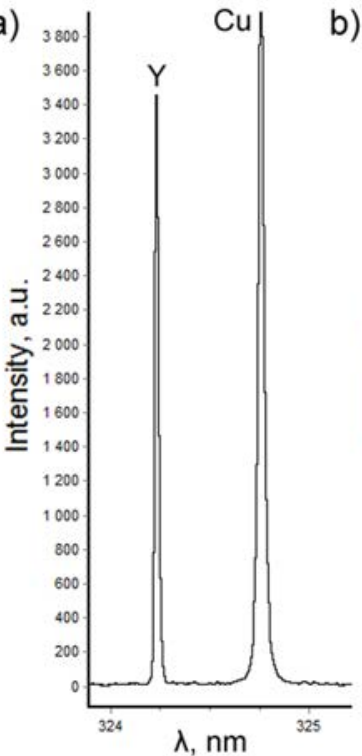

b)

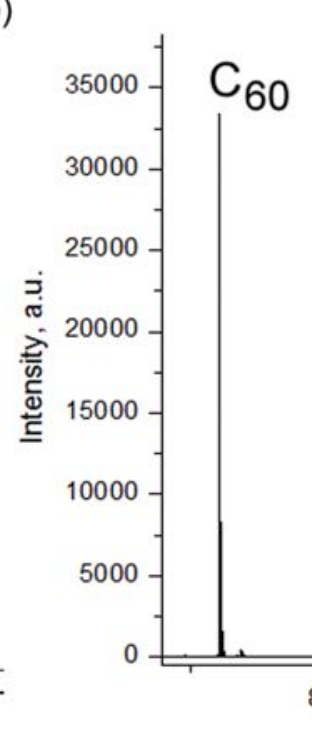

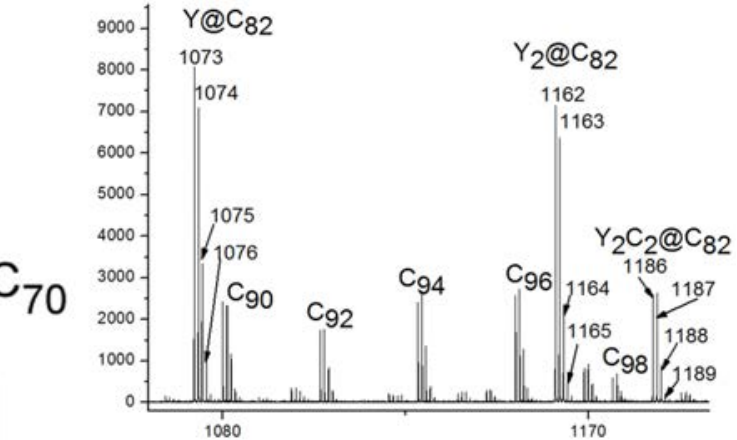

FIG. 6. Results of atom emission and positive-ion mass spectral analysis of FM synthesized with $\mathrm{Y}_{2} \mathrm{O}_{3}$ under $64.8 \mathrm{kPa}$ and extracted by $\mathrm{CS}_{2}$ a) part of atom emission spectrum, b) part of mass spectrum 
TABLE 1. Analysis results of FM samples contained Y, synthesized under different pressure

\begin{tabular}{|c|c|c|c|c|c|c|c|}
\hline \multicolumn{8}{|c|}{ Pressure under which EMF synthesis was carried out } \\
\hline \multicolumn{2}{|c|}{$353 \mathrm{kPa}$} & \multicolumn{2}{|c|}{$98 \mathrm{kPa}$} & \multicolumn{2}{|c|}{$64.8 \mathrm{kPa}$} & \multicolumn{2}{|c|}{$32.4 \mathrm{kPa}$} \\
\hline $\mathrm{C}_{5} \mathrm{H}_{5} \mathrm{~N}$ & $\mathrm{CS}_{2}$ & $\mathrm{C}_{5} \mathrm{H}_{5} \mathrm{~N}$ & $\mathrm{CS}_{2}$ & $\mathrm{C}_{5} \mathrm{H}_{5} \mathrm{~N}$ & $\mathrm{CS}_{2}$ & $\mathrm{C}_{5} \mathrm{H}_{5} \mathrm{~N}$ & $\mathrm{CS}_{2}$ \\
\hline \multicolumn{8}{|c|}{ Y content at $1 \mathrm{mg} F M, \mathrm{mg}^{1}$} \\
\hline $0.99 \cdot 10^{-3}$ & $0.41 \cdot 10^{-3}$ & $12.1 \cdot 10^{-3}$ & $9.7 \cdot 10^{-3}$ & $10.6 \cdot 10^{-3}$ & $8.0 \cdot 10^{-3}$ & $5.17 \cdot 10^{-3}$ & $2.4 \cdot 10^{-3}$ \\
\hline \multicolumn{4}{|c|}{ Content Y@C82,wt\% } & \multicolumn{4}{|c|}{ Y@C82,Y2C2@C82, Y2@C82 } \\
\hline 1.2 & 0.5 & 14.5 & 11.2 & - & - & - & - \\
\hline
\end{tabular}

${ }^{1}$ Methodic error less than $5 \%$.

\section{Acknowledgements}

The work was supported by the Ministry of Education and Science of Russia (RussianJapanese joined project, Agreement N 14.613.21.0010, ID RFMEFI61314X0010).

\section{References}

[1] Yang S., Liu F., Chen C., Jiao M., Wei T. Fullerenes encaging metal clusters - clusterfullerenes. Chem. Commun., 2011, 47, P. 11822-11839.

[2] Meng J., Wang D.L., Wang P.C., J. Biological characterization of $\left[\mathrm{Gd} @ \mathrm{C}_{82}(\mathrm{OH})_{22}\right]$ n nanoparticles as fullerene derivatives for cancer therapy. Nanosci. Nanotechnol, 2010, 10(12), P. 8610-8616.

[3] Popov A.A., Yang S., Dunsch L. Endohedral fullerenes. Chem. Rev., 2013, 113, P. 5989-6113.

[4] Kareev I.E., Laukhina E., Bubnov V.P., Martynenko V.M., Lloveras V., Vidal-Gancedo J., Mas-Torrent M., Veciana J., Rovira C. Harnessing Electron Transfer from the Perchlorotriphenylmethide Anion to $\mathrm{Y} @ \mathrm{C}_{82}(\mathrm{C} 2 \mathrm{v})$ to Engineer an Endometallofullerene-Based Salt. Chem. Phys. Chem., 2013, 14, P. 1670.

[5] Churilov G.N. Plasma Synthesis of Fullerenes. Instruments and Experimental Techniques, 2000, 43(1), P. 110.

[6] Churilov G.N., Kratschmer W., Osipova I.V., Glushenko G.A., Vnukova N.G., Kolonenko A.L., Dudnik A.I. Synthesis of fullerenes in a high-frequency arc plasma under elevated helium pressure. Carbon, 2013, 62, P. 389-392.

[7] Terek T., Mika J. Gegush E. Emission spectrochemical analysis. MIR, 1982, 464 p. 